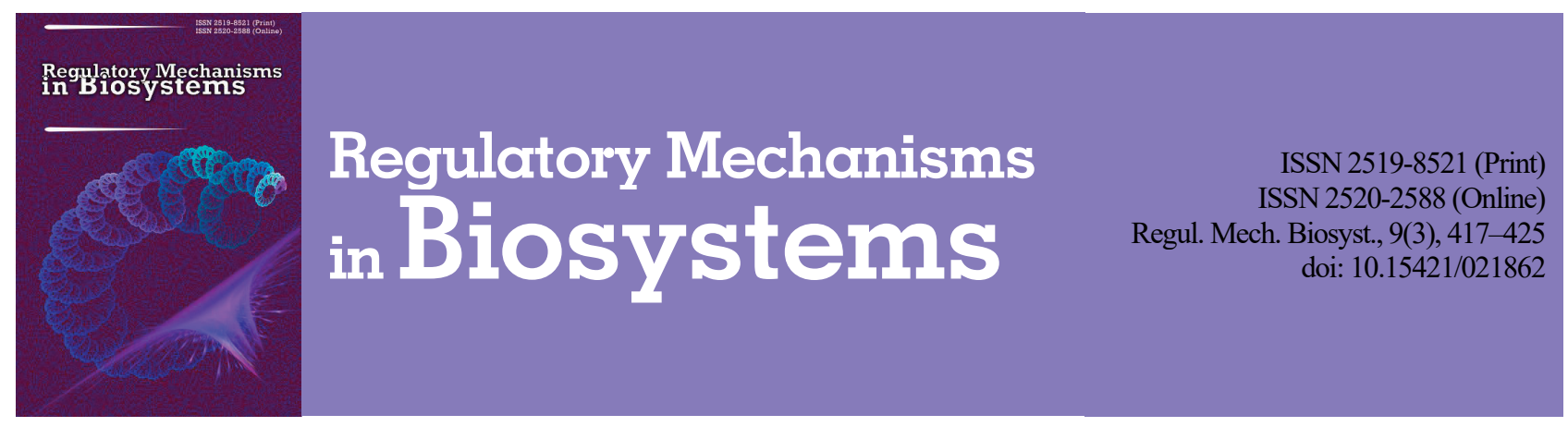

\title{
The features of summary background electric activity of the hypothalamus of rats under conditions of chronic caffeine alimentation
}

\author{
T. G. Turitskaya*, S. N. Lukashev**, V. P. Lyashenko*, G. G. Sidorenko*** \\ *Oles Honchar Dnipro National University, Dnipro, Ukraine \\ **Regional Clinical Hospital n.a. Mechnikov, Dnipro, Ukraine \\ ***Dnipro National University of Railway Ttransport n.a. Academician V. Lazaryan, Dnipro, Ukraine
}

Article info

Received 09.07.2018

Received in revised form 14.08.2018

Accepted 17.08.2018

Oles Honchar Dnipro National University, Gagarin ave., 72 Dnipro, 49010, Ukraine. Tel.: +38-056-372-58-76. E-mail:

tatyana.turickaya@gmail.com

Regional Clinical Hospital n.a. Mechnikov, Soborny District, 14, Dnipro, 49005, Ukraine. Tel.: +38-056-246-65-55.

E-mail:dr.lukashev@gmail.com

Dnipro National University of Railway Transport n.a. Academician V. Lazaryan, Lazaryana st., 2,

Dnipro, 49010, Ukraine

Tel.: +38-056-776-59-47.

E-mail:

morepisem83@gmail.com
Turitskaya, T. G., Lukashev, S. N., Lyashenko, V. P., \& Sidorenko, G. G. (2018). The features of summary background electric activity of the hypothalamus of rats under conditions of chronic caffeine alimentation. Regulatory Mechanisms in Biosystems, 9(3), 417-425. doi:10.15421/021862

One of the factors of the environment which essentially shifts homeostasis is diets which contain caffeine. The aim of the study was to find out the basic characteristics of background electrical activity of trophotrophic and ergotrophic zones of the hypothalamus in conditions of chronic caffeine alimentation. Experiments were carried out on non-linear white male rats. The first group consisted of control animals $(n=22)$. The second group $(n=24)$ was represented by the animals that were given pure caffeine in an amount of $150 \mathrm{mg} / \mathrm{kg} /$ day with their meal. The registration on a electrohypothalamogram was carried out in conditions of acute experiment, every 2 weeks for 12 weeks. The spectral $\left(\mathrm{mkV}^{2}\right)$ and the normalized power (\%) of electrohypothalamogram waves were analyzed within the common frequency band. The analysis of the results allowed us to establish a certain specificity of the reaction of the neuronal system of the trophotropic and ergotropic zones of the rat hypothalamus to the effect of chronic caffeine alimentation. The main difference in the reactive state of electrophysiological indices in the trophotrophic zone of rats is the lack of a typical desynchronization from the 4th to the 8th week of the study and the hypersynchronization after 12 weeks of the experiment. The most probable mechanism that explains the results obtained is the ultra-powerful GABA-ergic modulation of this zone, the main energy-accumulating center. Perhaps, this powerful inhibitory resource in this cerebral locus is the main stress-limiting factor that makes this zone of the central nervous system of rats less sensitive to caffeine exposure. Instead, under the influence of chronic caffeine load in the ergotropic zone of the hypothalamus, after 6 weeks of the experiment desynchronous high-frequency rhythms dominated. During the subsequent time of the experiment, we observed a decrease in both low-frequency and high-frequency components of the electrohypothalamogram of this zone. This gives reason to assume that the key component of the neurophysiological response of the posterior hypothalamus of rats to the caffeine ration is the powerful glutamatergic effects on the pre-synaptic and post-synaptic neurons under conditions of reactive exhaustion of local neurosynthetics. Caffeine depletion of the hypothalamic neurotransmission at the end of the experiment is replaced by an effective adaptive ergotropic restoration of neurosynthetic activity in this locus of the central nervous system of rats. Thus, caffeine has a powerful activating effect on the ergotropic function of the posterior hypothalamus of rats. Such a difference in the chronic effect of caffeine on the trophotropic and ergotropic zone of the rat hypothalamus is primarily due to the different mediator support of these zones underlying their physiological purpose. GABA is the main mediator of the trophotropic zone and the main neurotransmitter of its synchronous activity. At the same time, neurotransmitter support of the ergotropic zone is represented by glutamate, which, along with other agents, implements its desynchronous activity. Since caffeine stimulates excitation, activating the pathways traditionally associated with motivational and motor reactions in the brain, it can be assumed that this explains the fact of a more powerful influence of caffeine precisely on the ergotrophic zone of the hypothalamus.

Keywords: brain activity; trophotropic and ergotropic zone of the hypothalamus; sodium caffeine benzoate; rat; chronic caffeine alimentation.

\section{Introduction}

The hypothalamus plays a key role in controlling a wide range of vegetative, humoral and behavioral responses. From this point of view, the complex of such reactions has rather prolonged and ambiguous homeostatic consequences (Yoo \& Blackshaw, 2018). At the same time, the hypothalamus is quite sensitive to the metabolic status of the organism. Using the principle of negative feedback, this structure still prenatally controls the hormonal axis of the sexual, adrenal steroid hormones and thyroid hormones (Sominsky et al., 2018). The hypothalamus is the central chain of maintenance of a certain vegetative tone and the provision of any activity. Functional classification of the hypothala- mus identifies the areol nuclei of the ergo- and trophotropic zones that control the autonomic balance and have different neurotransmitter assistances. The gamma of neuro-endorrhizal reactions of the hypothalamus is also manifested in a certain emotional state and in the direction of complex behavioral reactions (Kalsbeek et al., 2014). It is known that the launch and regulation of stress reactions are carried out by the structures of the reticulum-limbic-neo-cortical system of the brain, the leading role in which belongs to the hypothalamus. There are many scientific papers that highlight the role of these nervous structures in providing adaptive-compensatory responses in organ systems and adaptive behavior formation (Meerson, 1993; Pshennikova, 2000; Vejn, 2003; Baldwin, 2006; Kazakov \& Natrus, 2005). With the help of biochemical, mor- 
phological, genetic and to a lesser extent, neurophysiological methods, it has been shown that these reactions are primarily carried out directly in the human brain and animals that are characterized by a large variety in the chronic effects of arbitrary factors (Lucassen et al., 2006; McEwen, 2008; Gunnar et al., 2009). That is why the hypothalamus has long been recognized as fundamental in the control and coordination of homeostatic activity. Historically, this was seen from the point of view of the large neuroendocrine control system, resulting from the processing of signals by the hypothalamus and the transfer of their results to the pituitary gland. Through these actions, the endocrine signals are integrated throughout the body, modulating a wide range of physiological processes. More recently, control of the hypothalamus over the autonomic nervous system was increasingly recognized as a powerful additional modulator of peripheral tissues. Nevertheless, the neuroendocrine and autonomic control pathways emerging from the hypothalamus are not separate processes. They act as the only integrated regulatory system, much more subtle and complex, than when every process is considered in isolation. Consequently, hypothalamic regulation should be considered as a summation of neuroendocrine and vegetative effects. It is believed that neural regulation is targeted and rapid, while hormonal regulation is more stable and widespread.

The direct recording of the electrical activity of neuronal populations is an extremely important diagnostic tool in the study of the functional activity of a certain central nervous system structure that is widely used throughout the world. The standard procedures for recording and analyzing brain electrical activity are widely recognized, but there is still a question about the interpretation of the results, especially of deep brain structures, such as the hypothalamus, which are involved in a large number of physiological reactions. That is why it is quite difficult to systematize and compare the findings of various researchers and scientific laboratories. We decided to solve this issue partially by means of chronic animal studies.

One of the factors of the environment, which essentially shifts homeostasis, is diets that include caffeine. Over the last decade, the use of such products has become massive, especially for coffee and tea. Today, coffee is one of the most popular beverages in the world, whose consumption has doubled over the past thirty five years $(9.5$ billion $\mathrm{kg}$ per year) (Ploshchyk, 2013; Kryvokulskyy \& Kondras, 2014; Bunn et al., 2015). It is well known that coffee is one of the few beverages of natural origin, consisting of substances of both organic and inorganic origin, which substantially affect almost all structures and systems of the human body (Fernstrom, 2000; Geel et al., 2005; Grosso et al., 2017; Poole et al., 2017). Establishing links between coffee consumption and different states and diseases has become widely studied (Grosso et al., 2017), but often with contrasting outcomes. The main safety problems arise in the ratio of caffeine (trimethylxanthine) as the main constituent of coffee. A toxic dose is $10 \mathrm{~g}$ of caffeine per day for adults (one cup of coffee contains $80-175 \mathrm{mg}$ of caffeine, depending on the preparation and type of grains). Coffea arabica contains twice as much caffeine as Coffea robusta. The highest content of caffeine is in Espresso coffee (100 mg $50 \mathrm{ml}$ ).

Caffeine is the most studied component, since it acts in a cell through several mechanisms and has several application points. It is an adenosine receptor antagonist (Ralevic \& Burnstock, 1998), an inhibitor of phosphodiesterase, a calcium channel synthesizer, an antagonist of GABA-ergic receptors (Daly, 2007). Physiological features of the action of caffeine on the central nervous system have been investigated by I. P. Pavlov and his collaborators. It has been shown that caffeine has a directed effect on the processes of inhibition and excitation of the cerebral cortex and may be an indicator of the strength of the nervous processes. In addition, optimal doses of caffeine normalize the processes of nervous activity with their violations. It has been shown that at a concentration of $3.3 \mathrm{mg} / \mathrm{kg}$ it improves mental activity (Battig \& Welzl, 1993). Paraxanthin, a major product of caffeine metabolism, is an even more active blocker of adenosine receptors (Viani, 1993). The action of adenosine on its own receptors depends on the type of receptor and the tissue or cell where the receptor is located. When blocking the adenosine receptors with caffeine, the concentration of adenosine in the plasma increases, due to which its systemic effects become more active. At the systemic level, adenosine enhances sympathetic tone, increases the concentration of catecholamines, the overall peripheral vascular resistance and production of renin. There is evidence (Scher et al., 2004) that during migraine attacks, the concentration of adenosine in the head and neck vessels increases by $68 \%$. Since caffeine is a blocker of several types of adenosine receptors, the effects of adenosine after taking caffeine should be less pronounced, which is likely to weaken the attack. But one should not forget that in some cases, the use of a large amount of caffeine may be the opposite of a trigger headache. This is due to increased cerebral blood flow and stimulation of the sympathetic nervous system (Echeverri et al., 2010). That is, coffee and caffeine can have both a positive and a negative effect on the system and the body as a whole, due to the content of other biologically active substances. On the one hand, there is strong evidence of positive effects of coffee/caffeine consumption for a number of chronic diseases, including some types of cancer (endometrium, prostate, colorectal and hepatic), cardiovascular diseases, and metabolic-related conditions (type 2 diabetes, metabolic syndrome), neurological conditions (Parkinson's disease, Alzheimer's disease, depression) (Grosso et al., 2017). On the other hand, caffeine is the most compromised physiological stimulant, which has side effects (Zulli et al., 2016), which can affect the state of the cardiovascular system. In addition, there is an increased risk of stroke and heart attacks without significant atherosclerotic damage to cerebral arteries. More importantly, prolonged traditional use of caffeine-based products and drinks can lead to apoptotic neurodegeneration, which will primarily be reflected in electrophysiological characteristics of the brain.

To date, there is no complete picture of the mechanisms of adapting the functional activity of the central structures to the long-term effects of environmental factors. In turn, the study of this issue can have significance as an essential aspect of the theory of adaptation processes and its practical application. Therefore, the purpose of the study was to elucidate the basic characteristics of the background electrical activity of the hypothalamus in conditions of chronic caffeine alimentation.

\section{Materials and methods}

The research has been carried out in accordance with the existing international requirements and norms of humane attitude towards animals. Experiments were performed on non-linear white male rats. At the beginning of the study their body mass was $125-140 \mathrm{~g}$. The animals lived in common sanitary conditions with a standard diet (Zapadnjuk et al., 1983). To obtain heterogeneity of emotional-stress reactions and their comparison in animals of the studied groups, preliminary testing was conducted to identify individual patterns of their behaviour (Gray, 1974). In addition, we tried to use rats with a more or less homogeneous genotype (from some parents). The first group consisted of control animals $(n=22)$, which during the whole experiment lived under standard conditions. The second group $(n=24)$ was represented by animals that received food "Caffeine sodium benzoate" (Darnitsa) in the amount of $150 \mathrm{mg} / \mathrm{kg} \cdot$ day (Govindwar et al., 1984; Georgiev et al., 1993; Yadegari et al., 1995; Antonelli-Ushirobira et al., 2010; Yadegari et al., 2016).

The registration of the background electrical activity of the hypothalamus was carried out using the stereotactic biopotential withdrawal method (Buresh et al., 1962) in an acute experiment in a subgroup of $3-$ 4 animals, every two weeks during the entire 12-week study. In addition, from the investigated areas of the rat's hypothalamus, 10-12 recordings of background electrical activity were made. As is known (Trahtenberg, 2001), for the majority of biological indicators used in studies, the minimum number of observations is 25 . Also, this approach is convenient for clinical practice (Metodycheskye rekomendacyy, 1999). After each experiment, the localization of the electrode tip at the frontal sections of the brain was verified (Buresh et al., 1962). The cuts into the brain (Fig. 1) of the rats were made using a freezing microtome. This procedure allowed reduction in the number of "extra" records in the subsequent statistical processing of data, thereby ensuring the reliability of the results. Surgical preparation for withdrawal of the electrohypothalamogram was performed after intra-abdominal administration of $20 \mathrm{mg} / \mathrm{kg}$ of ketamine and $50 \mathrm{mg} / \mathrm{kg}$ of sodium thiopental (Abramov, 1986; Derymedved' et al., 2001). The anesthetised animal was fixed in a stereotactic SEZ-2 device 
(on the design of Y. M. Belenov), which was located in a shielded room. The trepanation of the skull was carried out over the posterodial subzone of the cortical region at coordinates: $2-3 \mathrm{~mm}$ ulterior to the bregma and $5-6 \mathrm{~mm}$ lateral to the sagittal suture in the region of the intersection of the Bregma point with the horizontal and interraural axis. A prerequisite for a clear separation of the electrical activity of the hypothalamus was the fairly rigid mounting of the rat's head at three points (jaw and two auditory holes). After trepanation of the skull, a unipolar electrode (platinum, diameter $100 \mu \mathrm{m}$ ) was inserted into the ergotrophic and trophotropic zones of the hypothalamus in accordance with the stereotactic coordinates of the rat atlas (Paxinos and Watson, 1986). The reference electrode was placed on the anus of the animal, and grounding - in the region of the tail.

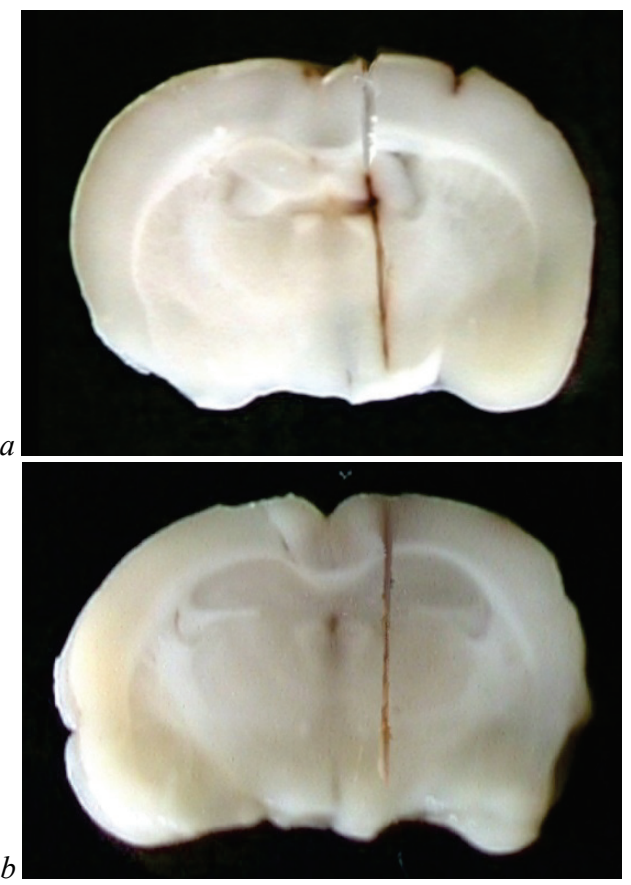

Fig. 1. Verification of localization of electrodes (frontal cuts of the brain of the rat): $a$ - anterior hypothalamic area, $b$-dorsal hypothalamic area

The coordinates of the structures were determined by the stereotactic atlas (Paxinos \& Watson, 2013). Coordinates of the anterior hypothalamic area: bregma $=-1.4 \mathrm{~cm}$, lateral axis $=0.8 \mathrm{~cm}$, interraural axis $=$ $9.0 \mathrm{~cm}$, the coordinates of the drooping hypothalamic area: bregma $=-2.3 \mathrm{~cm}$, lateral axis $=0.3 \mathrm{~cm}$, interraural axis $=8.0 \mathrm{~cm}$. After the restoration of the motor activity of the rat, which was determined by the disappearrance of the background electrical activity of narcotic spindles, the recording of the electrohypothalamogram began. In order to exclude short-term effects of caffeine on the ergotrophic and trophotropic zone of the hypothalamus, the registration of electrical activity was carried out 24-26 hours after the last administration of the substance.

The background electric activity of the hypothalamus was recorded using a standard complex electrophysiological equipment with a 16-bit ADC with a sampling frequency of $512 \mathrm{~Hz}$ (OO Bohomolets Institute of Physiology, Kyiv). The frequency characteristics of the amplifiers were chosen to ensure adequate recording of low-frequency oscillations (deltarange). The epoch of registration at removal of background electrical activity from each zone was 1-2 minutes. Before digitizing, the signals received were amplified with the help of an amplifier (O. Bohomolets Institute of Physiology, Kyiv). The results were processed using the Math CAD 2014 application package. Through the software, in all records of the main rhythms of the FEA, the duration of the analysis period was $10 \mathrm{~s}$ with sampling frequency of df, which was $0.1 \mathrm{~Hz}$. Rhythms and their power were obtained by the Fourier digital conversion method. To remove edge effects, a Hamming window was used. The spectral (absolute) power $\left(\mathrm{mV}^{2}\right)$ and the normalized (relative) power (\%) of electropyographic wave volumes within the generally accepted frequency ranges were analyzed (Vorob'eva \& Koljadko, 2007). The statistical processing of the results of the study was conducted using the Origin 6.0 Professional program using the method of pair comparisons and correlation analysis; the methods of variation statistics using the computer program Statistica 5.0 (StatSoft Inc., USA). The reliability of the differences between control and experimental data was determined using the non-parametric Mann-Whitney criterion for $\mathrm{P}<0.05$.

\section{Results}

The first stage of this work was registration with a further analysis of the native records of background electrical activity of the trophotropic zone of the rat hypothalamus in the studied groups (Fig. 2). Already at this stage of the work it was possible to visually note the difference in time between the experimental parameters of experimental rats. As we can see from Figure $2 d$, there was an increase in wavelengths both in the low-frequency range $(0.3-7.0 \mathrm{~Hz})$ and in the high-frequency range $(8-30 \mathrm{~Hz})$ compared with the data obtained in this group of animals in two weeks. The increase in the power of low-frequency waves may indicate, in our opinion, the species-specific features of the neurotransmitter in this species, which was reflected in the modulation of the background electrical activity of the trophotropic zone of the hypothalamus.

Analysis of the obtained data should be further elaborated on the dynamics of the basic rhythms of background electrical activity, which was recorded in the trophotropic zone of the hypothalamus. The statistical processing of all bioelectric signals of the anterior zone of the hypothalamus of the rat experimental group allowed us to reveal the following.

The rhythm with a frequency of oscillations of $0.5-4.0 \mathrm{~Hz}$ remained the dominant in the total electrohypothalamogram (trophotropic zone) of the animals of the experimental group during the whole time of the study. The analysis of spectral power in this frequency range showed the following. In the characteristic of the general dynamics of absolute power parameters of the delta-like activity of the caffeine group rats, it was possible to identify three phases with periods of $2-4,6-8$ and $10-12$ weeks from the beginning of the experiment. The maximum values were recorded, respectively, in $2\left(23.9 \pm 3.2 \mathrm{mV}^{2}\right), 6\left(30.2 \pm 2.2 \mathrm{mV}^{2}\right)$ and 12 $\left(36.9 \pm 4.1 \mathrm{mV}^{2}\right)$ weeks of the experiment. Comparing the result with control data (Fig. 3), the following should be highlighted. Only in the beginning (after 2 weeks) and at the end (after 12 weeks) of observation, were absolute power indices of delta-like activity in the total electrohypothalamogram of rats in the experimental group significantly higher $(\mathrm{P}<0.05)$ for the corresponding control values. And from 4 to 10 weeks of the experiment, on the contrary - the value of the control group reliably $(\mathrm{P}<0.05)$ exceeded the data of the experimental group.

In contrast to the spectral power, the dynamics of relative power indices in the frequency range of $0.5-4.0 \mathrm{~Hz}$ in the total electrohypothalamogram of rats in the experimental group was biphasic with periods of 2-6 and 8-12 weeks from the beginning of the experiment. For each phase, a gradual increase in the percentage of the delta-like activity from the minimum to the maximum values was characteristic. In general, the percentage of delta-rhythm in the total background electrical activity of the trophotrophic zone of the hypothalamus of the caffeine group rats varied between $62-78 \%$ during the experiment. Comparing the obtained result of the experimental group of rats with similar control data (Fig. 4), one can distinguish the following. In the first phase of the experiment (26 weeks), there was a tendency to increase the relative performance of the delta-like activity in the total electrohypothalamogram of the caffeine group rats in relation to control. For the second phase, after 8-10 weeks of the experiment, there was a characteristic tendency to reduction in these data relative to the control values, which only at the end of the observation (after 12 weeks) were significantly $(\mathrm{P}<0.05)$ higher than the control data.

In contrast to the dynamics of spectral power in the frequency range of $0.5-4.0 \mathrm{~Hz}$, changes in the spectral power parameters of experimental rats for the range of $4-8 \mathrm{~Hz}$ were biphasic. The first phase lasted from 2 to 8 weeks of the study, which was characterized by a gradual decrease in absolute power index of theta-like activity in the total electrohypothalamogram from 9.3 to $3.7 \mathrm{mV}^{2}$. The second phase lasted from 10 to 12 weeks of observation, during which these values decreased from 6.4 to $5.9 \mathrm{mV}^{2}$. Comparing the result of the experimental group's 
rats to the control data (Fig. 3), the following should be noted. Only in the beginning (after 2 weeks) and at the end (after 12 weeks) was the absolute power performance of the theta-like activity of the caffeine group rats significantly $(\mathrm{P}<0.05)$ higher than similar control data. In the period from 4 to 10 weeks from the beginning of the experiment on the contrary - it was significantly $(\mathrm{P}<0.05)$ lower.
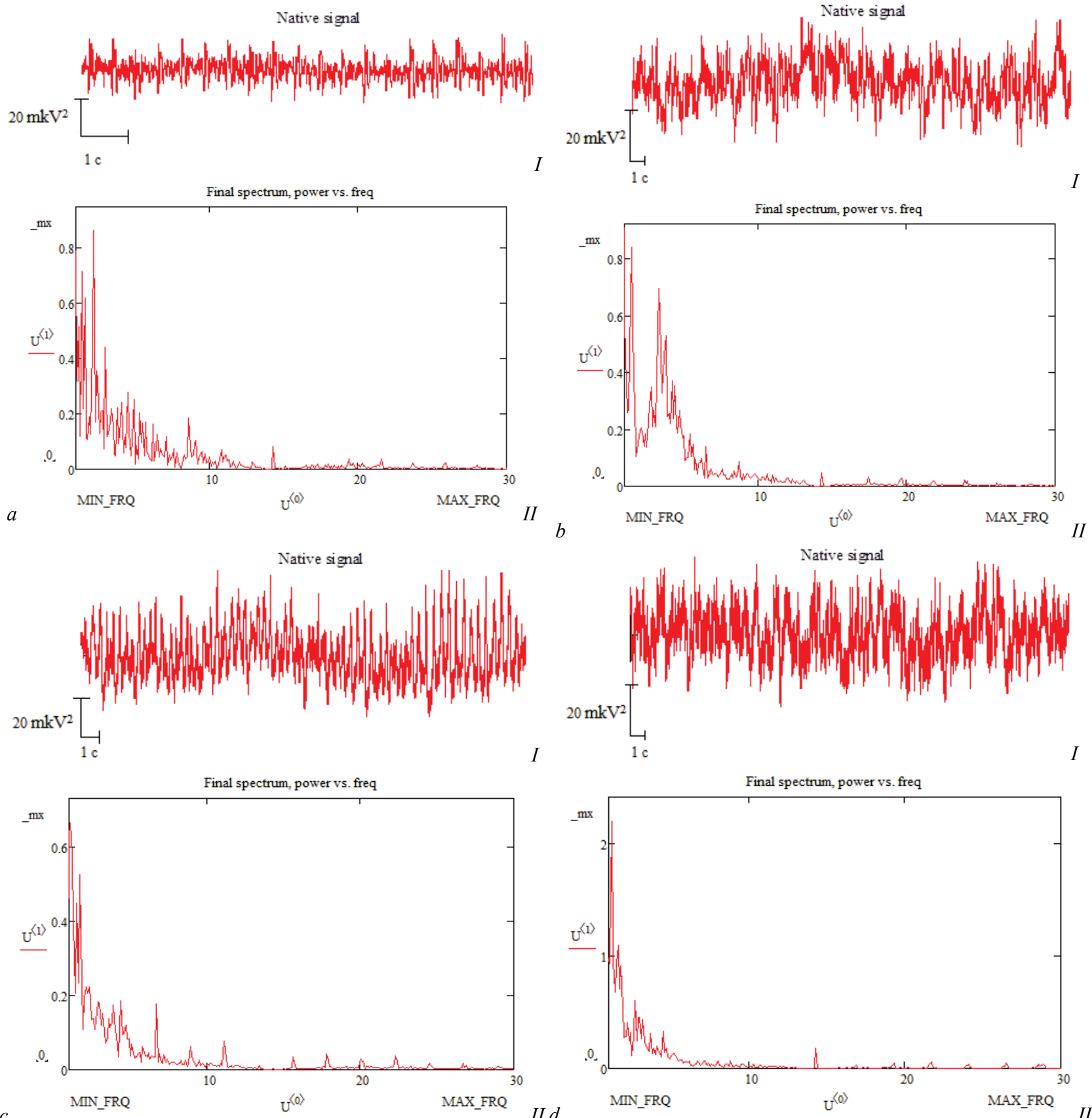

Fig. 2. The native recording $(I)$ and the spectral graph $(I I)$ of the total background electrical activity of the trophotropic zone of the hypothalamus in animals of control $(a, b)$ and experimental $(c, d)$ groups: $a, b$-after 2 weeks of study, $c, d$-after 10 weeks of study

The dynamics of percentage power indices in the frequency spectrum of $4-8 \mathrm{~Hz}$ in the total electrohypothalamogram of the caffeine group rats was also biphasic with periods of 2-6 and 8-12 weeks from the beginning of the experiment. For each phase, a gradual decrease in the percentage of the theta-rhythm in the total background electrical activity of the trophotropic zone of the hypothalamus from the maximum to the minimum values was characteristic. In general, this indicator fluctuated within $10-24 \%$. Attention is drawn to the fact that only after 2 and 10 weeks of the experiment, was the percentage of theta-like activity in the electrohypothalamogram of rats in the experimental group significantly $(\mathrm{P}<0.05)$ higher than the similar control parameters (Fig. 4).

Similar to the dynamics of theta-like activity, there were changes in both spectral and normalized power parameters in the total electrohypothalamogram of the caffeine group rats in the frequency range of $8-13 \mathrm{~Hz}$. These changes were biphasic, with time periods of $2-6$ and $8-12$ weeks from the start of the experiment. In addition, both absolute and relative values varied from maximum to minimum. At the same time, the spectral indices of the power of alpha-like activity in the total electrohypothalamogram of rats in the experimental group fluctuated within 1.00 $2.86 \mathrm{mV}^{2}$, and normalized - within 2.6-8.7\%. In addition, in most cases, the observed result in caffeine group rats was significantly $(\mathrm{P}<0.05)$ lower than similar control data (Fig. 3, 4).

The rhythm with a frequency of $13-35 \mathrm{~Hz}$ was the least expressed in the total background electrical activity of the ergotrophic zone of the hypothalamus of experimental rats. The overall dynamics of both spectral and normalized power parameters of beta-like activity was threephase. For absolute power indicators, the time periods of each phase changed after 2-6, 8-10 and 12 weeks from the beginning of the observation. At the same time, they underwent a gradual increase from the minimum to the maximum values. In general, this indicator varied within 
the range of 1.6-2.5 $\mathrm{mV}^{2}$. Comparing the results of the caffeine group rats with the control data, it should be noted that only at the end of the experiment were these values significantly $(\mathrm{P}<0.05)$ greater than the result of control (Fig. 3). And in the period from 2 to 8 weeks - it was significantly lower $(\mathrm{P}<0.05)$. For the relative power indices, the time periods of each phase changed after 2-4, 6-8 and 10-12 weeks from the beginning of the experiment. If the first two phases were characterized by a gradual increase in the percentage of beta-like activity in the total electrohypothalamogram of caffeine group rats from the minimum to maximum values, then at the end of the observation (the third phase), on the contrary, their decrease. In general, the percentage of beta-rhythm in the total electrohypothalamogram varied within $4-7 \%$. Comparing the result with control data (Fig. 4), it should be noted that only 8-10 weeks from the beginning of the experiment, these values were significantly greater than control.

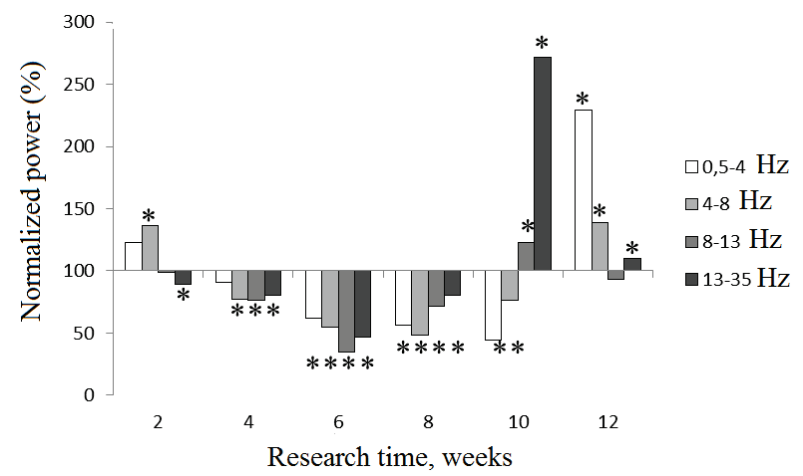

Fig. 3. Changes in normalized power indexes of the waves of the total background electrical activity of the trophotropic zone of the hypothalamus of animals of the experimental group relative to the values of this indicator in the control group rats in the correspondding weeks of the experiment (\%): the stars above the columns represent a significant change in the background electrical activity of the trophotrophic zone of the hypothalamus in the experimental group animals relative to the control of the Mann-Whitney criterion $(\mathrm{P}<0.05)$

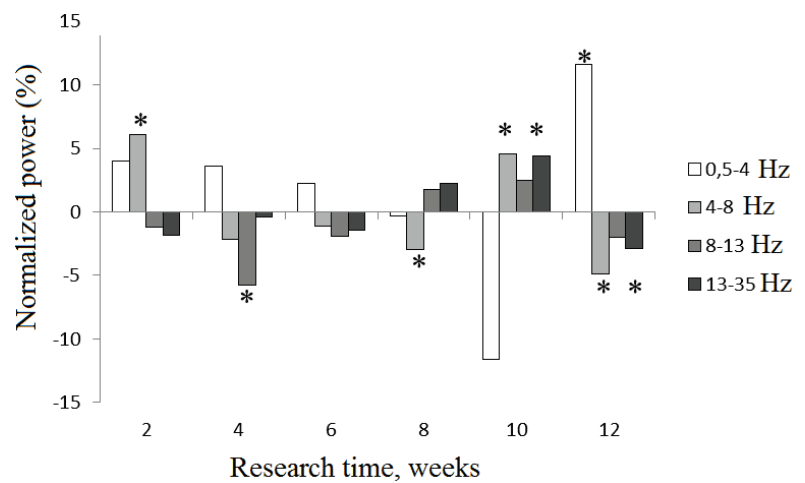

Fig. 4. Changes in normalized power indexes of the waves of the total background electrical activity of the trophotropic zone of the hypothalamus of animals of the experimental group relative to the values of this indicator in the control group rats in the corresponding weeks of

the experiment (\%): the designations are the same as in Fig. 3

The second stage of this work was registration with further analysis of the native records of the background electrical activity of the ergotrophic zone of the hypothalamus of the rats of the studied groups (Fig. 5), where certain differences were also noted. Over time, the study showed an increase in the power spectrum by 1.5 times, which was reflected in the frequency distribution of power (Fig. $5 g$ ). But it should be noted that in the beginning and at the end of the study, the dominant power values were recorded in low frequency bands $(0.3-3.0 \mathrm{~Hz})$, and the lowest values were recorded in the range of $14-30 \mathrm{~Hz}$. Further mathematical analysis allowed us to reveal the following.

Delta-like activity remained the dominant over the entire time of the study in both the spectral and the normalized ratio in the total electrohypothalamogram (ergotropic zone). In the dynamics of spectral power in- dexes in the frequency range of $0.5-4.0 \mathrm{~Hz}$, three phases with maxima were identified at 2, 6 and 12 weeks from the beginning of the observation. The power values in these time periods were $26.2 \pm 1.4,31.9 \pm 2.3$ and $40.0 \pm 3.2 \mathrm{mV}^{2}$, respectively. Comparing the result with similar control indicators, the following should be noted (Fig. 6). Only in the beginning (after 2 weeks) and at the end of the experiment (after 12 weeks) were the absolute values of delta-rhythm power in the total electrohypothagramogram significantly $(\mathrm{P}<0.05)$ greater than the corresponding control values. In another time period (after 6-10 weeks), the data of the animals of the caffeine group were significantly $(\mathrm{P}<0.05)$ lower than the data of control.

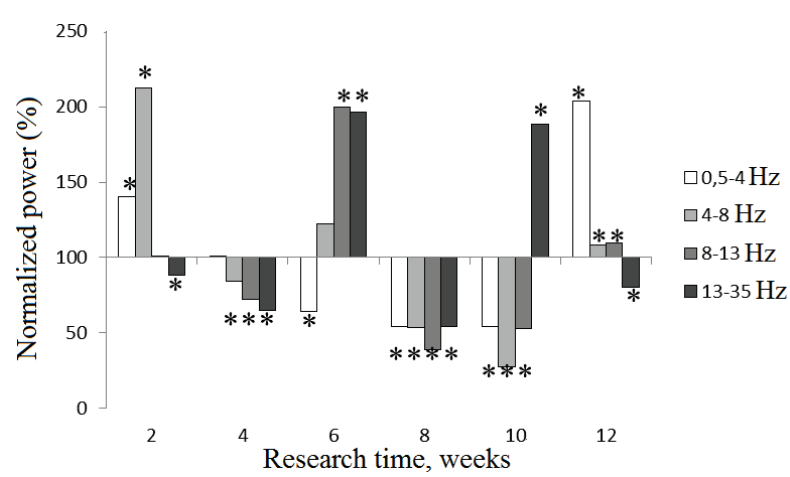

Fig. 6. Changes in normalized power indexes of the waves of the total background electrical activity of the ergotropic zone of the hypothalamus of animals of the experimental group relative to the values of this indicator in the control group rats in the corresponding weeks of the experiment (\%): the stars above the columns represent a significant change in the background electrical activity of the ergotrophic zone of the hypothalamus in the experimental group animals relative to the control of the Mann-Whitney criterion $(\mathrm{P}<0.05)$

In contrast to the dynamics of spectral power parameters in the frequency range of $0.5-4.0 \mathrm{~Hz}$, the changes in normalized power performance were biphasic: the first phase lasted from 2 to 6 weeks of experiment, the second - from 8 to 12 weeks from the beginning of the study. In addition, in these time periods, a gradual increase in the percentage of delta-like activity in the total electrohypothalamogram was noted, with the registration of maximum values for each phase through $6(65.7 \pm 3.8 \%)$ and $12(77.3 \pm 6.1 \%)$ weeks of experiment. The minimum values for this frequency range were recorded 8 weeks after the start of observation, when the percentage of delta rhythm in the total electrohypothalamogram of the erythropoies of the hypothalamus did not exceed $43.8 \pm 2.1 \%$. When comparing the result of the rats to which caffeine was administered with similar control data, the following should be highlighted (Fig. 7). In general, the importance of the percentage of delta-rhythm in the total electrohypothalamogram of animals in the experimental group was close to the control. Only 6, 8 and 12 weeks from the beginning of the experiment, were they significantly $(\mathrm{P}<0.05)$ different.

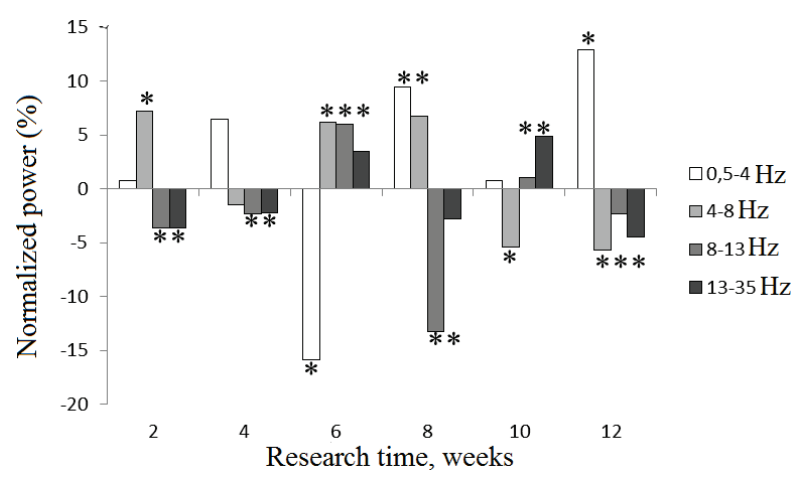

Fig. 7. Changes in normalized power indexes of the waves of the total background electrical activity of the ergotropic zone of the hypothalamus of animals of the experimental group relative to the values of this indicator in the control group rats in the corresponding weeks of the experiment (\%): the designations are the same as in Fig. 6 

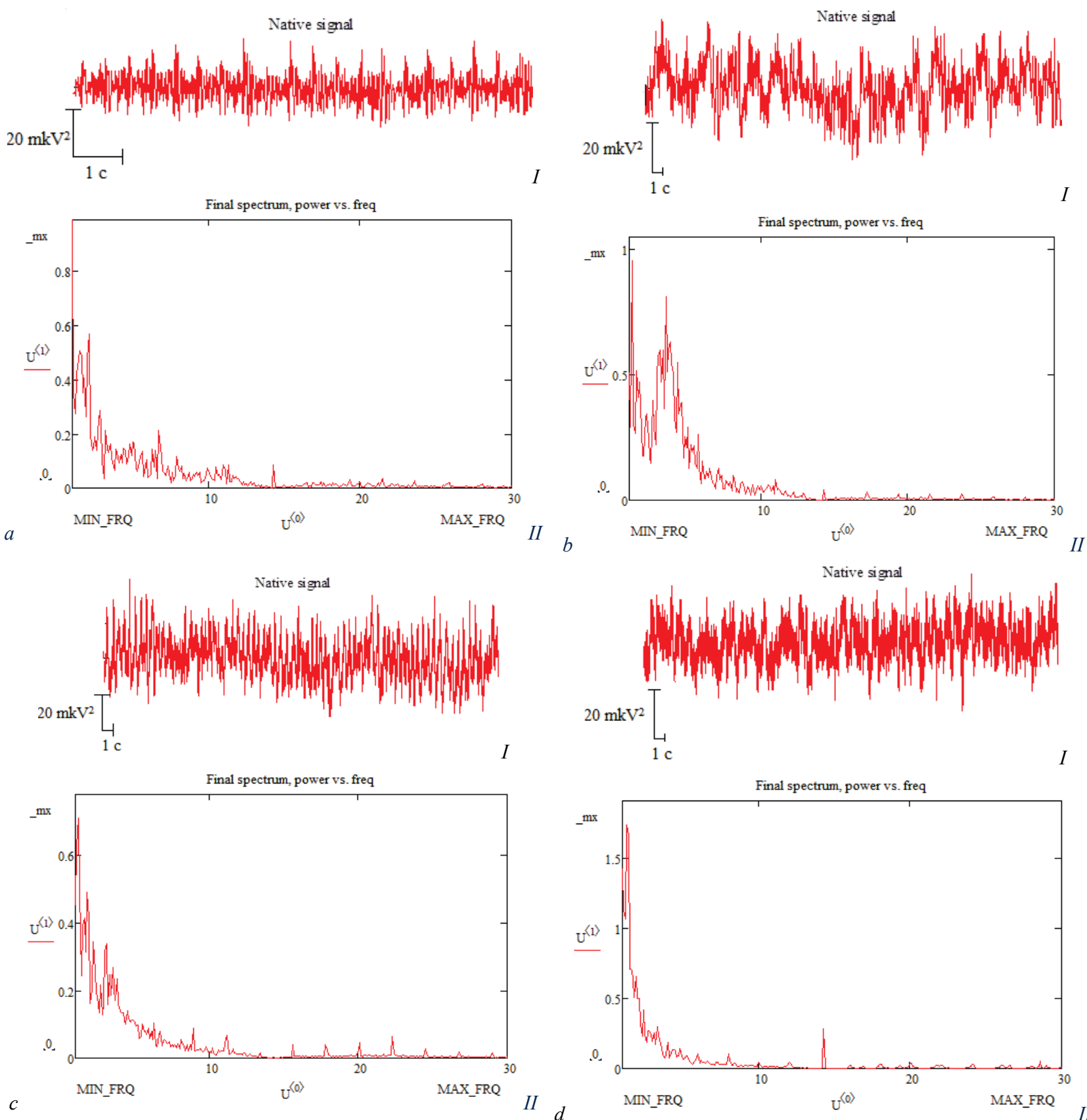

Fig. 5. The native recording $(I)$ and the spectral graph $(I I)$ of the total background electrical activity of the ergotropic zone of the hypothalamus in animals of control $(a, b)$ and experimental $(c, d)$ groups: the designations are the same as in Fig. 2

Almost twice as much theta-like activity was expressed in the total electrohipothalamogram of rats in the experimental group. The dynamics of absolute power indices in the frequency range of $4-8 \mathrm{~Hz}$ was threephase with periods of 2-4, 6-10 and 12 weeks from the beginning of the study. The maximum power indexes were recorded at the beginning of the experiment (after 2 weeks) and amounted to $13.6 \pm 0.8 \mathrm{mV}^{2}$, and the minimum - after 4 and 10 weeks, where they did not exceed 5-6 $\mathrm{mV}^{2}$. Comparing the obtained result of experimental rats with similar control indices, it should be noted that only in the beginning (after 2 weeks) and at the end (12 weeks) from the beginning of the experiment, was the spectral power of the theatrical rhythm in the total electrohypotalamogram significantly higher $(\mathrm{P}<0.05)$ for control values (Fig. 1). In the middle of the study (after 4-10 weeks), on the contrary, there was a significant $(\mathrm{P}<0.05)$ decrease in the investigated indicator in relation to control.

The dynamics of normalized power parameters in the frequency range of $4-8 \mathrm{~Hz}$ was almost the same as the spectral power in the total electrohypothalamogram of the caffeine group rats. In general, three phases could also be distinguished in changes in the percentage of thetarhythm in the total electrohypothalamogram. The first phase lasted from
2 to 6 weeks of the experiment and was characterized by a gradual decrease of these parameters from $29.0 \%$ to $17.7 \%$. The second phase (810 weeks) was characterized by a sharp increase in the percentage of theta-like activity up to $33.2 \%$ (which was the maximum for this frequency band), which further decreased threefold and did not exceed $11 \%$ ( 10 weeks of experiment). At the end of the observation ( 12 weeks) there was a slight restoration of the percentage of theta-rhythm in the total electrohypothagramogram to $14.0 \%$. Comparing the results for the experimental group of animals to similar control data, one can distinguish the following (Fig. 7). For the time period from 2 to 8 weeks the study was characterized by a significant $(\mathrm{P}<0.05)$ increase in the percentage of theta rhythm in the total electrohypothalamogram of the ergotrophic zone of the hypothalamus of the caffeine group rats in relation to control. Only at the end of the observation (after 10-12 weeks) was this indicator significantly $(\mathrm{P}<0.05)$ lower than the similar values of control.

The least high-frequency rhythm was expressed in the total electrohypothalamogram of rats in the experimental group. Thus, for the frequency range of 8-13 Hz in the dynamics of absolute power parameters, three phases of the data changes, which lasted from 2 to 4 , from 6 to 10 
and 12 weeks of experiment, were characteristic. The maximum absolute values of the power of alpha-like activity in each of the time periods were recorded, respectively, in $2\left(4.0 \pm 0.2 \mathrm{mV}^{2}\right), 6\left(4.8 \pm 0.7 \mathrm{mV}^{2}\right)$ and $12\left(2.7 \pm 0.2 \mathrm{mV}^{2}\right)$ weeks from the beginning of the study. And the smallest result for the frequency range of $8-13 \mathrm{~Hz}$ in the total electrohypothalamogram of the caffeine group rats was recorded after 10 weeks, where it was $2.0 \pm 0.9 \mathrm{mV}^{2}$. In relation to control (Fig. 6), the values mentioned above, characteristic for the experimental group, almost always significantly differed $(\mathrm{P}<0.05)$ among themselves.

In the dynamics of the percentage of alpha-like activity in the total electrohypothalamogram of the caffeine group rats from 2 to 8 weeks of experiment, a gradual increase in the data from 8 to $13 \%$ was observed. After 10 weeks of the experiment, a sharp decrease in the percentage of alpha rhythm to $4.5 \pm 0.5 \%$ was observed, which at the end of the observation (after 12 weeks) although recovered to $5.6 \pm 0.3 \%$, did not exceed the initial values. Comparing the obtained result with similar control values (Fig. 7), it should be noted that almost always (except for 6 and 10 weeks) normalized power parameters in the frequency range of $8-13 \mathrm{~Hz}$ of experimental rats were significantly lower $(\mathrm{P}<0.05)$.

The most stable and similar in dynamics both of absolute and relative power indices in the total electrohypothalamogram of the caffeine group rats were changes in the frequency range of $13-35 \mathrm{~Hz}$. It was characterized by a gradual increase in both the spectrum and the percentage of beta-like rhythm from 2 to 8 weeks from the beginning of the experiment. Moreover, at the beginning of the observation (after 2 weeks), these data were minimal, and after 8 weeks - the maximum. At the end of the experiment (after 10-12 weeks) there was a gradual decrease in both absolute and relative power indices of beta-like activity in the total electrohypothalamogram. Comparing the result obtained in experimental rats with similar control data, it should be noted that these differences were always valid (Fig. 6, 7).

\section{Discussion}

The role of the hypothalamus in providing vital functions and maintaining homeostasis is beyond doubt. The fact that it is an important center for integrating the physiological functions of the body has been confirmed by many authors (Agadzhanjan, 1983; Malyshev \& Manuhina, 1998; Morita et al., 2005). In addition, the hypothalamus acts as the central link, which first reacts to the action of arbitrary stress factors and provides adaptation of the organism to new conditions (Meerson, 1993; Pshennikova, 2000).

On the basis of numerous studies in the hypothalamus, the zones with mostly sympathetic (ergotropic hypothalamic region) and parasympathetic (trophotropic) effects were identified, and the hypothalamus itself was considered as the center of integration of the vegetative system (Talalaenko et al., 2002; Vejn, 2003; Gasser et al., 2006). Such a distribution on the ergotropic and trophotropic zone is functional and biological in character, indicating participation in the provision of functional activity. Thus, in the anterior zone of the hypothalamus, a cholinergic synaptic transmission predominates, and in the posterior region there is a catecholateral synaptic transmission. Changing the prevalence under certain conditions of neurotransmitters in the brain may serve as a strong modulator of background electrical activity (Majkova et al., 2004). It is likely that under the conditions of various stressors, the resistance of a living organism will be determined by the features of the central neurochemical organization in the ergotropic and trophotropic zones of the hypothalamus. Investigation of neurochemical mechanisms of stress state showed the participation of adrenergic systems in their neurotransmitter maintenance and the participation of cholinergic systems in their inhibition. In turn, under conditions of stressors, activation of the catecholateral neurotransmitter in the brain is observed. This is accompanied by an increase in mediation of norepinephrine in the paraventricular nucleus of the hypothalamus and mediated norepinephrine activation of the hypothalamic-pituitary-adrenal axis (Darlington et al., 1992; Bartamesz et al., 1994; Pacak et al., 1995). However, a continued mismatch between these neurotransmitter systems can lead to the development of negative stress states, which is accompanied by a change in vegetative functions and paroxysmal activity of background electrical activity, which origin- nally occurs on the hypothalamus. The electrical activity of the hypothalamus, in turn, is one of the indicators of the functional state, which plays an important role in the adaptive-compensatory reactions of the organism. In addition, incredibly complex functional bonds exist not only between different zones of the hypothalamus, but also between its nerve and endocrine elements. All this allows the body to adapt in the optimal and most energy-saving way. Caffeine is one of the most important stimulant drugs (Dimpfel, 2013). The use of caffeine in our studies allowed us to assess the state of the trophic and ergotropic zones of the hypothalamus and the possible mechanisms for their participation in adaptation processes.

An analysis of electrohypothalamograms showed that in the trophotropic zone of the hypothalamus, after two weeks of caffeine alimentation, an increase in the absolute and normalized power of the main deltarhythm was observed. Our previous studies (Turic'ka et al., 2015, 2016) showed that this growth is much smaller than in the neocortex and hippocampus under similar conditions, but is clearly indicative of the activation of mediator synthetic systems. The most specific for this focus of the rat brain is the significant inhibition of both the power and the representation of high-frequency rhythms of the electrohypothalamogram after 4-8 weeks of the experiment. This is probably due to an increase in the reactivity of GABA-ergic modulation in hypermedia neurotransmitters. After 8-10 weeks of the experiment, there is a tendency to increase desynchronizing effects due to the probable exhaustion of the GABA resource, which is again sharply restored after 12 weeks - in the period of a significant increase in absolute and normalized theta-rhythm power in contrast to the high-frequency rhythms. It can be assumed that this mechanism is unique to the trophotropic zone of the rat hypothalamus in connection with its functional purpose of the energy storage center, which is dominated by the synergistic effects of GABA. Perhaps such a powerful inhibitory resource in this cerebral locus is the main stresslimiting factor that makes this zone of the central nervous system of rats less sensitive to caffeine exposure.

In the ergotropic zone of the hypothalamus, after a week of caffeine loading, a significant increase in the absolute and normalized power of the dominant synchronous rhythms was observed. This may be due to hypermediative neurosynthetic activity of presynaptic neurons due to activation of intracellular rianoindin receptors by caffeine. After $2-4$ weeks of the experiment in the ergotropic zone, there was a decrease in the absolute and normalized power of both synchronous and desynchronous rhythms, indicating the onset of primary exhaustion of neurotransmission. But after 6 weeks, the power and the presence of high-frequency rhythms are likely to increase, which is most likely due to the modulating effect of glutamate on post-synaptic responses as a result of the activation of cambial postsynaptic receptors. In the continuation of 810 weeks, this effect disappears and the hypodemic neurotransmitter is restored. This is confirmed by the relative decrease in power of both the dominant low-frequency and high-frequency rhythms. The last two weeks of the experiment clearly demonstrate the initial adaptive-adaptive reversion of presynaptic neurosynthetic, thus providing an ergotropic ultra low-frequency sympathetic resource of the posterior hypothalamus. This is evidenced by the restoration of the initial physiological domination of low-frequency rhythms, both in absolute and in normalized power.

Such a difference in the chronic effect of caffeine on the trophic and ergotropic zone of the rat hypothalamus is primarily due to the different mediator support of these zones, which underlies their physiological purpose. GABA is the main mediator of the trophotropic zone and the main neurotransmitter of its synchronous activity. At the same time, neurotransmitter support of the ergotropic zone is represented by glutamate, which, along with other agents, implements its desynchronous activity. Studies in rats have shown (Lazarus et al., 2011) that caffeine stimulates excitation by activating pathways traditionally associated with motivational and motor reactions in the brain. To such paths, in a certain way, belongs also the ergotropic zone of the hypothalamus, which regulates the vegetative provision of the indicated processes. Perhaps this explains the fact of the more powerful influence of caffeine precisely on the ergotropic zone of the hypothalamus.

It is also impossible to ignore the different part of the investigated structures in the hypothalamic-pituitary-adrenocortical axis. Since caf- 
feine is a nonselective adenosine antagonist, it can modulate the metabolic pathways in this axis (Nabbi-Schroeter et al., 2018; Karaismailoglu et al., 2017; Xu et al., 2012), which will somehow affect the adaptive responses. First of all, it concerns adrenal glands that react sensitively to the formation and implementation of adaptive-compensatory reactions.

\section{Conclusions}

The results of the experiment prove some specificity of the reaction of the neuronal system of the tropho- and ergotropic zones of the rat hypothalamus to the effect of chronic caffeine alimentation.

The main difference in the reactive state of electrophysiological indices in the trophotropic zone of rats is the absence of a typical desynchronization from the 4th to the 8th week of the study and the hypersynchronization after 12 weeks of the experiment. The most likely mechanism that explains the results obtained is the ultra-powerful GABA-ergic modulation of this zone, the main energy-accumulating center. Stresslimiting GABA-ergic resource of the indicated zone significantly reduces its sensitivity to caffeine exposure in rats.

Under the influence of chronic caffeine load in the ergotropic zone of the hypothalamus, after 6 weeks of study desynchronous high-frequency rhythms dominated. During the rest of the study, we observed a decrease in both the low-frequency and high-frequency components of the electrohypothalamogram of this zone. This forms the view that the key component of the neurophysiological response of the posterior rat hypothalamus to the caffeine diet is the powerful glutamatergic effects on the pre- and post-synaptic neurons under conditions of reactive exhaustion of local neurosynthetic. Caffeine depletion of the hypothalamic neurotransmission at the end of the experiment is replaced by an effective adaptive-adaptive ergotropic restoration of neurosynthetic activity in this locus of the central nervous system of rats. Thus, caffeine has a powerful activating effect on the ergotropic function of the posterior rat hypothalamus.

\section{References}

Agadzhanjan, N. A. (1983). Adaptacija i rezervy organizma [Adaptation and body reserves]. Fizkul'tura i Sport, Moscow (in Russian).

Antonelli-Ushirobira, T. M., Kaneshima, E. N., Gabriel, M., Audi, E. A., Marques, L. C., \& Mello, J. C. (2010). Acute and subchronic toxicological evaluation of the semipurified extract of seeds of guarana (Paullinia cupana) in rodents. Food and Chemical Toxicology, 48(7), 1817-1820.

Baldwin, A. L. (2006). Mast cell activation by stress. Methods in Molecular Biology, 315, 349-360.

Bartamesz, V., Aubry, J. M., \& Steimer, T. (1994). Stressor-specific increase of vasopressin mRNA in paraventricular hypophysiothrophic neurons. Neuroscience Letters, 170, 35-38.

Battig, K., \& Welzl, H. (1993). Psychopharmacological profile of caffeine. In: Garatini, S. (Ed.). Caffeine, coffee and health. Raven Press, New York. Pp. 213-253.

Berthou, F., Goasduff, T., Dréano, Y., \& Ménez, J. F. (1995). Caffeine increases its own metabolism through cytochrome P4501A induction in rats. Life Sciences, 57(6), 541-549.

Bunn, C., Läderach, P., Rivera, O. O., \& Kirschke, D. (2015). A bitter cup: Climate change profile of global production of Arabica and Robusta coffee. Climatic Change, 129(1-2), 89-101.

Buresh, J., Petran', M., \& Zahar, I. (1962). Jelektrofiziologicheskie metody isledovanija [Electrophysiological methods of investigation]. Izdatel'stvo Inostrannoj Literatury, Moscow (in Russian).

Daly, J. W. (2007). Caffeine analogs: Biomedical impact. Cellular and Molecular Life Sciences, 64(16), 2153-2169.

Darlington, D. N., Barraclough, C. A., \& Gann, D. S. (1992). Hypotensive hemorrhage elevates corticotrophin-releasing hormone messenger ribonucleic acid (mRNA) but not vasopressin mRNA in the rat hypothalamus. Endocrinology, 130, 1281-1288.

Derimedved', L. V., Percev, I. M., \& Shuvalova, E. V. (2001). Vzaimodejstvie lekarstv i jeffektivnost' farmakoterapii [Interaction of drugs and the effectiveness of pharmacotherapy]. Megapolis, Kharkov (in Russian).

Dimpfel, W. (2013). Pharmacological classification of herbal extracts by means of comparison to spectral EEG signatures induced by synthetic drugs in the freely moving rat. The Journal of Ethnopharmacology, 149(2), 583-589.

Echeverri, D., Montes, F. R., Cabrera, M., Galán, A., \& Prieto, A. (2010). Caffeine's vascular mechanisms of action. International Journal of Vascular Medicine, 2010, article ID 834060.
Fernstrom, J. D. (2000). Can nutrient supplements modify brain function? American Journal of Clinical Nutrition, 71(6), 1669S-1675S.

Gasser, P. J., Lowry, C. A., \& Orchinik, M. (2006). Corticosterone-sensitive monoamine transport in the rat dorsomedial hypothalamus: Potential role for organic cation transporter 3 in stress-induced modulation of monoaminergic neurotransmission. Journal of Neuroscience, 26(34), 8758-8766.

Geel, L., Kinnear, M., \& de Kock, H. L. (2005). Relating consumer preferences to sensory attributes of instant coffee. Food Quality and Preference, 16, 237-244.

Georgiev, V., Johansson, B., \& Fredholm, B. B. (1993). Long-term caffeine treatment leads to a decreased susceptibility to NMDA-induced clonic seizures in mice without changes in adenosine A1 receptor number. Brain Research, 612(1-2), 271-277.

Govindwar, S. P., Kachole, M. S., \& Pawar, S. S. (1984). In vivo and in vitro effects of caffeine on hepatic mixed-function oxidases in rodents and chicks. Food and Chemical Toxicology, 22(5), 371-375.

Gray, J. (1972). Tne psychology of fear and stress. Academic Press, New York.

Grosso, G., Godos, J., Galvano, F., \& Giovannucci, E. L. (2017). Coffee, caffeine, and health outcomes: An umbrella review. The Annual Review of Nutrition, 37, 131-156.

Gunnar, M. R., Herrera, A., \& Hostinar, C. E. (2009). Stress and early brain development. Encyclopedia on Early Childhood Development. Centre of Excellence for Early Childhood Development, Montreal, Quebec. Pp. 1-8.

Kalsbeek, A., Bruinstroop, E., Yi, C. X., Klieverik, L., Liu, J., \& Fliers, E. (2014). Hormonal control of metabolism by the hypothalamus-autonomic nervous system-liver axis. Frontiers of Hormone Research, 42, 1-28.

Karaismailoglu, S., Tuncer, M., Bayrak, S., Erdogan, G., Ergun, E. L., \& Erdem, A. (2017). The perinatal effects of maternal caffeine intake on fetal and neonatal brain levels of testosterone, estradiol, and dihydrotestosterone in rats. Naunyn-Schmiedeberg's Archives of Pharmacology, 390(8), 827-838.

Kazakov, V. N., \& Natrus, L. V. (2005). Modulation of neuronal impulse activity of the anterior hypothalamus as a functional basis of the mechanisms underlying hypothalamic control. Neurophysiology, 37, 463-474.

Krivokul'skij, O. B., \& Kondras', N. M. (2014). Osnovni tendenciji spozhivannja kavi v sviti ta Ukraini: Suspilno-geografichnij aspect [Major trends of coffee consumption in the world and Ukraine: Human-geographical aspect]. Ekonomichna ta Social'na Geografija, 69, 299-307 (in Ukrainian).

Lazarus, M., Shen, H. Y., Cherasse, Y., Qu, W. M., Huang, Z. L., Bass, C. E., Winsky-Sommerer, R., Semba, K., Fredholm, B. B., Boison, D., Hayaishi, O., Urade, Y., \& Chen, J. F. (2011). Arousal effect of caffeine depends on adenosine A2A receptors in the shell of the nucleus accumbens. The Journal of Neuroscience, 31(27), 10067-10075.

Lucassen, P. J., Heine, V. M., Muller, M. B., van der Beek, E. M., Wiegant, V. M., De Kloet, E. R., Joels, M., Fuchs, E., Swaab, D. F., \& Czeh, B. (2006). Stress, depression and hippocampal apoptosis. CNS and Neurological Disorders Drug Targets, 5(5), 531-546.

Majkova, T. N., Lukashjov, S. N., \& Piramidov, M. A. (2004). Javlenie samoreguljacii elektrogeneza central'noj nejronal'noj predachi mozga cheloveka [The phenomenon of self-electrogenesis central neuronal predachi human brain]. Vestnik Rossijskoj Akademii Estestvenih Nauk, 4(1), 64 (in Russian).

Malyshev, J. I., \& Manuhina, E. B. (1998). Stress, adaptacija i oksid azota [Stress, adaptation and nitric oxide]. Biohimija, 63(7), 992-1006 (in Russian).

McEwen, B. S. (2008). Understanding the potency of stressful early life experiences on brain and body function. Metabolism, 57(2), 11-15.

Meerson, F. Z. (1993). Adaptacionnaja medicina: Mehanizmy i zashhitnye effekty adaptacii [Adaptation medicine: Mechanisms and protective effects of adaptation]. Hypoxia Medical LTD, Moscow (in Russian).

Metodicheskie rekomendacii po klinicheskomu ispytaniju lekarstvennyh sredstv v Ukraine (1999) [Methodical recommendations for the clinical trial of medicinal products in Ukraine]. Kyiv (in Russian).

Morita, K., Sekiyama, A., \& Rokutan, K. (2005). Stress and central neuroendocrine networks. No To Shinkei, 57(5), 397-406.

Nabbi-Schroeter, D., Elmenhorst, D., Oskamp, A., Laskowski, S., Bauer, A., \& Kroll, T. (2018). Effects of long-term caffeine consumption on the adenosine A1 receptor in the rat brain: An in vivo pet study with $\left[{ }^{18} \mathrm{~F}\right] \mathrm{CPFPX}$. Molecular Imaging and Biology, 20(2), 284-291.

Pacak, K., Palkovits, M., \& Kvetnasky, R. (1995). Effects of various stressors on in vivo notepinephrine release in the hypothalamic paraventricular nucleus and on the pituitary-adrenocortical axis. Annals of the New York Academy of Sciences, 771, 115-130.

Paxinos, G., \& Watson, C. (2013). The rat brain in stereotaxic coordinates. 7th ed. Academic Press, Imprint.

Ploshchyk, N. (2013). The world coffee sector under conditions of the second wave of the economic recession. Journal of Intercultural Management, 3(5), 91-101.

Poole, R., Kennedy, O. J., Roderick, P., Fallowfield, J. A., Hayes, P. C., \& Parkes, J. (2017). Coffee consumption and health: Umbrella review of meta-analyses of multiple health outcomes. British Medical Journal, 359, j5024. 
Pshennikova, M. G. (2000). Fenomen stressa [The phenomenon of stress]. Patologicheskaja Fiziologija i Eksperimental'naja Terapija, 2, 24-31 (in Russian).

Ralevic, V., \& Burnstock, G. (1998). Receptors for purines and pyrimidines. Pharmacological Reviews, 50(3), 413-492.

Scher, I., Stewart, W. F., \& Lipton, R. B. (2004). Caffeine as a risk factor for chronic daily headache: A population-based study. Neurology, 63(11), 2022-2027.

Sominsky, L., Jasoni, C. L., Twigg, H. R., \& Spencer, S. J. (2018). Hormonal and nutritional regulation of postnatal hypothalamic development. The Journal of Endocrinology, 237(2), 47-64.

Talalaenko, A. N., Pankrat'ev, D. V., \& Goncharenko, N. V. (2002). O monoaminergicheskih i aminokislotergicheskih mehanizmah zadnego gipotalamusa v realizacii antiaversivnyh effektov anksiossedativnyh i anksioselektivnyh sredstv na razlichnyh modeljah trevogi [About monoaminergic and aminoacidic mechanisms of the posterior hypothalamus in the realization of antiinversion effects of anksiosedative and anxioselective agents in various anxiety models]. Jeksperimental'naja i Klinicheskaja Farmakologija, 65(5), 22-26 (in Russian).

Trahtenberg, I. M. (Ed.). (2001). Osnovnye pokazateli fiziologicheskoj normy u cheloveka [The main indicators of physiological norm in humans]. Avicena, Kyiv (in Russian).

Turic'ka, T. G., Lukashov, S. M., \& Ljashenko, V. P. (2016). Efekty vplyvu hronichnoji kofejinovoji alimentaciji na pokazniky fonovoji elektrychnoji aktivnosti neokorteksu shhuriv [Effects of chronic caffeine alimentation on the performance indicators of rat neocortex background electrical activity] Experimental Physiology and Biochemistry, 75(3), 11-16.
Vejn, A. M. (2003). Vegetativnye rasstrojstva [Autonomic dysfunction]. MIA, Moscow (in Russian).

Viani, R. (1993). The composition of coffee. In: Garatini, S. (Ed). Caffeine, coffee and health. Raven Press, New York. Pp. 17-41.

Vorob'eva, T. M., \& Koljadko, S. P. (2007). Jelektricheskaja aktivnost' mozga (priroda, mehanizmy, funkcional'noe znachenie) [The electrical activity of the brain (the nature, mechanisms, functional significance)]. Eksperimental'naja i Klinicheskaja Medicina, 2, 4-11 (in Ukrainian).

Xu, D., Zhang, B., Liang, G., Ping, J., Kou, H., Li, X., Xiong, J., Hu, D., Chen, L. Magdalou, J., \& Wang, H. (2012). Caffeine-induced activated glucocorticoid metabolism in the hippocampus causes hypothalamic-pituitary-adrenal axis inhibition in fetal rats. PLoS One, 7(9), e44497.

Yadegari, M., Khazaei, M., Anvari, M., \& Eskandari, M. (2016). Prenatal caffeine exposure impairs pregnancy in rats. International Journal of Fertility and Sterility, 9(4), 558-562.

Yoo, S., \& Blackshaw, S. (2018). Regulation and function of neurogenesis in the adult mammalian hypothalamus. Progress in Neurobiology, in press.

Zapadnjuk, I. P., Zapadnjuk, E. A., Zaharija, E. A., \& Zapadnjuk, B. V. (1983). Laboratornye zhivotnye: Razvedenie, soderzhanie, ispol'zovanie v eksperimente [Laboratory animals: Breeding, content, use in experiment]. Vishha Shkola, Kyiv (in Russian).

Zulli, A., Smith, R. M., Kubatka, P., Novak, J., Uehara, Y., Loftus, H., Qaradakhi, T., Pohanka, M., Kobyliak, N., Zagatina, A., Klimas, J., Hayes, A., La Rocca, G., Soucek, M., \& Kruzliak, P. (2016). Caffeine and cardiovascular diseases: Critical review of current research. European Journal of Nutrition, 55(4), 1331-1343. 